\title{
Emergency Endoscopy During the SARS-CoV-2 Pandemic in the North of Italy: Experience from St. Orsola University Hospital—Bologna
}

\author{
A. Lauro ${ }^{1} \cdot$ N. Pagano ${ }^{1} \cdot$ G. Impellizzeri ${ }^{1} \cdot$ M. Cervellera ${ }^{1} \cdot$ V. Tonini ${ }^{1}$
}

Published online: 22 April 2020

(c) Springer Science+Business Media, LLC, part of Springer Nature 2020

This is a report of the daily experience from February 28 to April 5, 2020, collected by our Emergency Endoscopy Service during the COVID-19 (coronavirus disease 2019) pandemic in the North of Italy, throughout the pre-peak and peak phases.

The following description is related to the virus outbreak at St. Orsola University Hospital in Bologna (EmiliaRomagna district, Italy): The first COVID-19-positive patient was admitted to our hospital on February 28, 2020. Due to the pandemic course of the virus in Emilia-Romagna (district quarantine starting on March 8, 2020-4.5 million people) and in Italy (national lockdown starting on March 11, 2020-60 million people), St. Orsola University Hospital (1500 beds, founded in the sixteenth century) was fully devoted to the treatment of patients with COVID-19. Since then, routine activity has changed substantially; the need of ICU and ID (infectious disease) beds necessitated repurposing most of the operating rooms, wards, and patient suites to COVID-19 care. All physicians and surgeons switched their daily tasks to become temporary ICU and ID specialists. The crisis, due to the aggressiveness and rapid spread of the virus, affected other hospitals, necessitating admission of patients coming from the entire Emilia-Romagna and from other districts of the Northern Italy to our wards. Following

\footnotetext{
Editor's Note: This report is one of a series documenting the impact of the pandemic caused by the SARS-CoV-2 virus with resultant morbidity and mortality due to COVID-19. We would like for our readers to hear about experiences in regions in which the virus was particularly ferocious, such as in Northern Italy as reported by our colleagues Augusto Lauro et al., who provide a fascinating first-hand report of the planning, hard work, courage, skill, and dedication that provided needed endoscopic services to an epicenter of viral activity without infecting additional patients or caregivers.
}

A. Lauro

augustola@yahoo.com

1 Emergency Surgery and GI Department, St. Orsola University Hospital, Bologna, Italy
Lombardy, Emilia-Romagna suffered the greatest impact; to this date, the district paid its tribute to the virus with 19.100 infected and 2.400 fatalities, the peak on March 20 with more than 100 victims in 1 day. We are still deeply involved with a crisis, with doctors constrained to their hospitals to the present. In Italy, 109 physicians and surgeons have lost their lives fighting COVID-19.

Endoscopy entails a high risk of SARS-CoV-2 transmission due to (a) the short physical distance between patients and healthcare providers [1], (b) the presence of the putative SARS-CoV-2-binding site, the angiotensin-converting enzyme (ACE) 2 receptor highly expressed in the duodenal brush border [2], and (c) the oral-fecal mode of transmission as an alternative route of contagion [3-6]. Such as in other Italian districts with the highest peaks of COVID-19 incidence, our endoscopy service was centralized to our referral hospital in order to improve the response to the increasing number of COVID-19 admissions, reducing the district workload. In a rapid progression, our local healthcare system was challenged to the maximum level, threatening our ability to offer adequate care. We were forced to deal with these challenges through emergency brainstorming sessions, acting as a united medical-surgical community in order to define our action plan that was based on a practical strategy, reorganizing the hospital pathways of emergency endoscopy in order to avoid virus dissemination. We report our experience with emergency endoscopies in the COVID-19 era; the goal was to sustain a full emergency endoscopic capability despite the hospital overload due to SARS-CoV-2-infected patients.

Following recommendations released by the Italian Society of Digestive Endoscopy (S.I.E.D.) [7], all routine endoscopies were postponed and rescheduled. Instead, emergency endoscopies were performed on SARS-CoV-2-negative and positive patients; a negative-pressure room outside the endoscopy department was planned, but, at the beginning of the pandemic, the only practical possibility was to create a separate suite for SARS-CoV-2-positive patients needing 
endoscopic examination. Personal protective equipment (PPE) such as double gloves, filtering facepiece respirators (FFP2 or FFP3), water-resistant gowns, goggles, and shoe covers [8] was available inside the department, with attention placed on their safe disposal. In order to avoid the spread of virus among hospital personnel, we strictly regulated entry and exit into operating rooms and endoscopy suites. The minimum staff level (strictly necessary to perform urgent or unpostponable procedures) attended the department, and in order to minimize risks and the overuse of PPE, students together with trainees and other caregivers were not allowed to access the suite [9]. To preserve service continuity, concomitant exposure of staff with specialist skills was avoided [10]. Eventually, a strategy that entirely separated patients infected with SARS-CoV-2 from those who were not infected was clearly identified [11-24]. In our hospital, urgent endoscopies were carried out routinely from 08:00 to 20:00 in the endoscopy suite, whereas overnight they are performed in the ED. If the patient is in critical condition or requiring anesthetic assistance, the procedures are carried out in the operating room. During the virus outbreak, the ED was crowded with SARS-CoV-2-positive patients making it impossible to use any room for urgent endoscopy. For this reason, during the nightshift, the procedures were all performed in the operating room. Emergency endoscopy procedures were due to life-threatening gastrointestinal bleeding, foreign body ingestion, food bolus impaction, intestinal obstruction, caustic ingestion, and ascending cholangitis as reported in Table 1.

From February 28 to April 5, 2020, 38 urgent endoscopic procedures on adult patients were carried out, 31 (81\%) upper endoscopies and 7 (19\%) performed in the lower gastrointestinal tract. In $29(76 \%)$ patients, the indication was digestive bleeding diagnosed/treated by 23 EGDs and 6 colonoscopies. Among these procedures, 21(72\%) were carried out in the endoscopy suite and $8(28 \%)$ in the operating room. There were two foreign body removals, both performed in the operating room and two procedures due to caustic ingestion performed in the endoscopic suite. One intestinal obstruction and four patients with acute cholangitis were treated with endoscopic stenting and endoscopic drainage in the endoscopic suite. In one SARS-CoV-2-positive patient treated by ECMO (extracorporeal membrane oxygenation), EGD and colonoscopy were performed at the bedside; the patient suffered from diffuse mucosal bleeding due to acute gastritis and ileal hemorrhage without discrete bleeding sites, likely due to the anticoagulation. Thus far, we have not had any documented cases SARS-CoV-2 infections of patients or caregivers related to our endoscopic procedures. In order to evaluate our performance in this demanding setting, we compared these data to those obtained by our group in the same period of time in 2019 (Table 1). At that time, we performed 40 urgent endoscopic procedures, $32(80 \%)$ upper endoscopies and $8(20 \%)$ related to the lower gastrointestinal tract. In 30 patients (75\%), the indication was GI tract hemorrhage diagnosed/treated with 24 EGDs and 6 colonoscopies. Among these procedures, 27 (90\%) were carried out in the endoscopy suite and $3(10 \%)$ in the operating room. There was an EGD performed for food bolus obstruction performed in the endoscopy suite. Two intestinal obstructions were treated by endoscopic stenting in the endoscopy suite, whereas seven endoscopic drainages (and stenting when needed) were performed on patients affected by cholangitis. Among these procedures, five ERCPs were performed in the endoscopy suite and two in the operating room.

Apart from an increasing number of procedures performed in the operating room (+50\% in 2020), the analysis of our series shows no substantial differences among urgent endoscopic procedures during the COVID-19 era compared with the same period of the prior year (Table 1). This achievement was our goal since emergency procedures by definition cannot be postponed and are represented mostly by gastrointestinal hemorrhage that occurs independently of other factors such as natural disasters or pandemics.

During the reorganization of our service due to the virus outbreak, the implemented measures facilitated carrying the usual burden of endoscopic emergencies in spite of room redistribution and personnel reallocation. The creation of a dedicated route for SARS-CoV-2-positive patients, the institution of adequate training procedures with appropriate instructions to the staff, and a proper policy of PPE use

Table 1 Comparison of emergency endoscopy procedures performed in the same period of time in 2019 and 2020 (COVID era)

\begin{tabular}{|c|c|c|c|c|c|c|c|c|}
\hline & Upper GI bleeding & $\begin{array}{l}\text { Caustic } \\
\text { inges- } \\
\text { tion }\end{array}$ & $\begin{array}{l}\text { Foreign body } \\
\text { ingestion }\end{array}$ & $\begin{array}{l}\text { Food bolus } \\
\text { obstruction }\end{array}$ & Lower GI bleeding & $\begin{array}{l}\text { Intestinal } \\
\text { obstruc- } \\
\text { tion }\end{array}$ & Cholangitis & Total (OR) \\
\hline & Total (OR) & & Total (OR) & & Total (OR) & & Total (OR) & \\
\hline $\begin{array}{l}\text { February 28-April } \\
\text { 5, } 2019\end{array}$ & $24(3)$ & & & 1 & 6 & 2 & $7(2)$ & $40(5)$ \\
\hline $\begin{array}{l}\text { February 28-April } \\
\quad 5,2020\end{array}$ & $23(7)$ & 2 & $2(2)$ & & $6(1)$ & 1 & 4 & $38(10)$ \\
\hline
\end{tabular}

OR operating room, GI gastrointestinal 
avoided the risk of spreading the virus among patients and operators. As pointed out earlier, at present there is no documented transmission of SARS-CoV-2 infections to patients or caregivers attributable to our emergency endoscopies. Moreover, an important key point is the activity of trainees during the pandemic. In our hospital, trainees are essential to the management of the burden among patients infected by SARS-CoV-2, but, regarding endoscopy, our policy was to stop training in the urgent endoscopy suite in order to reduce the numbers of inside operators and their use of PPE. Due to the global pandemic, a reorganization of the emergency endoscopy service should be considered by all hospitals, based on efficient teamwork and cross-specialty collaboration, with a clearly delineated priority hierarchy for urgent procedures that are performed in a region according to a "hub-and-spoke" strategy due to the reduced number of staff members and the limited availability of hospital beds, endoscopy suites, operating rooms, and resources.

\section{References}

1. Repici A, Maselli R, Colombo M, et al. Coronavirus (COVID19) outbreak: what the department of endoscopy should know. Gastrointest Endosc. 3/14/2020.

2. Wan Y, Shang J, Graham R, et al. Receptor recognition by novel coronavirus from Wuhan: an analysis based on decade-long structural studies of SARS. J Virol. 3/17/2020.

3. To KK, Tsang OT, Chik-Yan Yip C, et al. Consistent detection of 2019 novel coronavirus in saliva. Clin Infect Dis. 2/12/2020.

4. Young BE, Ong SWX, Kalimuddin S, et al. Epidemiologic Features and Clinical Course of Patients Infected With SARS-CoV-2 in Singapore. JAMA. 3/3/2020.

5. Zhang J, Wang S, Xue Y. Fecal specimen diagnosis 2019 novel coronavirus-infected pneumonia. J Med Virol. 3/3/2020.

6. Gu J, Han B, Wang J. COVID-19: Gastrointestinal manifestations and potential fecal-oral transmission. Gastroenterology. 3/3/2020.

7. Italian Society of Digestive Endoscopy (Societá Italiana di Endoscopia Digestiva -SIED). Update 1 on emergency Coronavirus outbreak (Aggiornamento 1-Emergenza Coronavirus). http:// www.sied.it/ (accessed data on 10 April 2020) (Article in Italian).

8. Tse F, Borgaonkar M, Leontiadis GI. COVID-19: Advice from the Canadian Association of Gastroenterology for Endoscopy Facilities. https://www.cagacg.org/images/publications/CAGStatement-COVID-\&-Endoscopy.pdf/ (accessed data on 10 April 2020).

9. Wong TW, Lee CK, Tam W, et al. Cluster of SARS among medical students exposed to single patient, Hong Kong. Emerg Infect Dis. 2004;10:269-276.
10. Joint GI Society Message on COVID-19. https:// gi.org/2020/03/15/joint-gi-society-message-oncovid-19/ (accessed data on 10 April 2020).

11. Castro Filho EC, Castro R, Fernandes FF, et al. Gastrointestinal endoscopy during COVID-19 pandemic: an updated review of guidelines and statements from international and national societies. Gastrointest Endosc. 4/5/2020.

12. Han J, Wang Y, Zhu L, et al. Preventing the spread of COVID-19 in digestive endoscopy during the resuming period: meticulous execution of screening procedures. Gastrointest Endosc. 4/5/2020.

13. Han J, Kim EY. Sharing Our Experience of Operating an Endoscopy Unit in the Midst of a COVID-19 Outbreak. Clin Endosc. 2020;53:243-245.

14. Marchese M, Capannolo A, Lombardi L, et al. Use of a modified ventilation mask to avoid aerosolizing spread of droplets for short endoscopic procedures during coronavirus covid-19 outbreak. Gastrointest Endosc. 4/2/2020.

15. Ong J, Cross GB, Dan YY. Prevention of nosocomial SARS$\mathrm{CoV}-2$ transmission in endoscopy: international recommendations and the need for a gold standard. Gut. 4/2/2020.

16. Chiu PWY, $\mathrm{Ng} \mathrm{SC}$, Inoue $\mathrm{H}$, et al. Practice of endoscopy during COVID-19 pandemic: position statements of the Asian Pacific Society for Digestive Endoscopy (APSDE-COVID statements). Gut. 4/2/2020.

17. Ang TL, Li JW, Vu CK, et al. Chapter of Gastroenterologists professional guidance on risk mitigation for gastrointestinal endoscopy during COVID-19 pandemic in Singapore. Singapore Med J. 4/3/2020

18. Thompson CC, Shen L, Lee LS. COVID-19 in Endoscopy: Time to do more? Gastrointest Endosc. 3/28/2020.

19. Lui RN, Wong SH, Sánchez-Luna SA, et al. Overview of guidance for endoscopy during the coronavirus disease 2019 (COVID-19) pandemic. J Gastroenterol Hepatol. 3/31/2020.

20. Valdivia PC, le Grazie M, Gaiani F, et al. Separated pathways in the endoscopy unit for COVID-19 patients. Gastrointest Endosc. $3 / 27 / 2020$.

21. Soetikno R, Teoh AY, Kaltenbach T, et al. Considerations in performing endoscopy during the COVID-19 pandemic. Gastrointest Endosc. 3/27/2020.

22. Ang TL. Gastrointestinal endoscopy during COVID-19 pandemic. J Gastroenterol Hepatol. 3/26/2020.

23. Zhang Y, Zhang X, Liu L, et al. Suggestions for infection prevention and control in digestive endoscopy during current 2019-nCoV pneumonia outbreak in Wuhan, Hubei province, China. Endoscopy. 2020;52:312-314.

24. Sociedad Española de Patología Digestiva; Asociación Española de Gastroenterología. Recommendations by the SEPD and AEG, both in general and on the operation of gastrointestinal endoscopy and gastroenterology units, concerning the current SARS-CoV-2 pandemic (March, 18). Rev Esp Enferm Dig. 3/23/2020.

Publisher's Note Springer Nature remains neutral with regard to jurisdictional claims in published maps and institutional affiliations. 